\title{
Factors Impacting Job Performance and Role Attractiveness in Academic Directors and their Implications for Policy and Practice in Higher Education
}

\section{Introduction}

Higher education in Europe, Australia and the USA has undergone extensive change since the mid-80s as a result of universities having to demonstrate their efficiency and effectiveness (Holmes, 1993; Harvey \& Knight, 1996; Currie \& Newson, 1998). Universities now have to perform in an increasingly complex environment, responding to multiple and often conflicting demands and being asked to become more financially independent (de Boer \& Goedegebuure, 2009; Meek, Goedegeburre \& de Boer, 2010). These changes are unlikely to slow down in the future and Harvey and Knight (1996) and Currie and Newson (1998) provide the historical backdrop for why these changes continue to challenge universities many years later.

There is growing pressure to instil more professional management practices and quality leadership in universities along with a continuous supply of leaders who can provide ongoing quality performance (Meek, Goedegeburre \& de Boer, 2010). These changes and pressures have had a large impact on Australian academic staff members who indicate considerably lower satisfaction on management issues compared to other countries. This finding was based on a survey of 19 different countries with Australia ranking seventeenth on satisfaction (Coates et al., 2010). This increase in university managerialism is having an impact on the academic workforce. Hence, the importance of investigating the impact of this management trend on university staff is worthy of further research.

\section{Literature Review}

One of the most important groups of academic managers impacted by this managerialism are those managers charged with the responsibility for basic academic qualifications within 
schools and departments (Meek, Goedegeburre \& de Boer, 2010). In this paper, these individuals are referred to as Academic Directors and are responsible for the delivery as well as quality of a course (e.g. Bachelor of Commerce, Bachelor of Science in Physiotherapy or a Masters of Business Administration). These middle level managers are positioned between those in more senior roles of the university and the academics who teach the classes. The Academic Director in these circumstances must lead and manage using distributed methods of leadership (McRoy \& Gibbs, 2009) as they often lack formal authority (Vilkinas \& Ladyhewsky, 2012).

The literature in several countries stresses the importance of good working conditions in universities if an individual is able to complete their work effectively and efficiently (AlRubaish et al., 2009; Bellamy et al., 2003; Coates et al., 2009; Lazarsfeld Jensen \& Morgan, 2009; Lindner, 1998; Vilkinas, 2009; Wong \& Heng, 2009). The Academic Directors are no exception. Previously, their working relationship with their colleagues (Byrne et al., 2012; Wong \& Heng, 2009), workload formula (Byrne et al., 2012) and the nature of the program (Byrne et al., 2012) have been identified as having an influence on the Academic Directors' performance.

The Academic Director's role needs to be attractive so that appropriate staff within or external to the university will consider the role and lead the academic qualification effectively. The positive correlation between job satisfaction and organisational performance (Coates, et al., 2010) and job performance (Judge et al., 2001; Iaffoldano \& Muchinsky, 1985; Petty, et al., 1984) has been explored for many years. Ensuring that the Academic Director's role is attractive is one way of facilitating job satisfaction, quality performance and positive program outcomes. Several strategies have been noted in the literature to make this role more attractive. These include, having promotion criteria that recognises the contributions made by Academic Directors (Al-Rubaish et al., 2009; Coates et al., 2009; 
Lindner, 1998; Wong \& Heng, 2009), more allocated workload time (Coates et al., 2009), administrative support and greater recognition and credibility given to the role (Vilkinas, 2009). All of these strategies have been suggested as means of improving role attractiveness and reducing turnover in these positions.

Clearly, as previously published research suggests, there are significant factors that should be considered when designing any job, and in the case of this research, the Academic Director's role. The purpose of the present research was thus twofold. The first was to identify factors that impact on the role of the Academic Director and on their performance in particular as there little research in this area (Byrne, et al., 2012; Wong \& Heng, 2009). Very little is known about these middle level management positions and how they have been transformed by the new managerialism in universities (de Boer, Goedegebuure \& Meek, 2010). As a result, more research is needed as most has focussed on the top executive level. This is undeserved because these middle level manager positions are the connection between institutional strategy and implementation (de Boer, Goedegebuure \& Meek, 2010) and more should be understood about these pivotal roles. Further, it has been demonstrated that organisational performance is influenced by what happens at the middle rather than the top level (Currie \& Procter, 2005).

By gaining a better understanding of what these job factors are for these middle level positions, senior leaders in universities and the higher education sector may start to modify policies, procedures and practices, restructure work and/or innovation/training efforts accordingly. Academic Directors may also use this understanding to better prepare themselves for this role by undertaking situated leadership development. This type of development has been demonstrated to be more effective in academic environments if the leadership development involves experiential learning within the role, interaction with peers, and reflective practice (Deem, et al., 2007; Johnson, 2002; Ladyshewsky \& Flavell, 2012). 
Academic Directors may also use this information to discuss what they might need in their role to be more effective.

The second purpose of this research was to identify what factors would make the Academic Director's role more attractive. This, in turn, would facilitate recruitment and retention strategies for this important role. It is not unusual for academic staff, for example, to be told that they must undertake this role because it is their turn. This 'arm-twisting' does not always lead to the right candidate being selected for this important role. Many universities have also not paid serious attention to job design factors for this role. Hence, academic faculties may not be recruiting or retaining talented individuals well-suited to the Academic Director role if they have not considered the factors that make the role attractive.

\section{Methodology}

\section{Participants}

\section{Academic Directors}

Academic Directors $(n=101)$ from four large Australian metropolitan universities volunteered to complete a $360^{\circ}$ feedback survey, which was part of a leadership development program at each institution. Participation in the program was based on a first-come-firstserved basis. Participants were both self-selected and nominated by their Head of School. Hence, it is a sample of convenience and does not include participants who may have been reluctant to participate in training or individuals sent to the program as part of required performance management/development.

The Academic Directors were invited to respond to an online $360^{\circ}$ feedback survey and were encouraged to nominate others, with whom they worked closely, to participate in the survey as well. For the purposes of this study, these work colleague respondents were called Significant Others. Nomination of Significant Others by the Academic Directors was based on a belief that these individuals would provide them with useful feedback. This approach is 
particularly suitable when the $360^{\circ}$ feedback process is used for developmental purposes, rather than for performance evaluation, and when a number of Significant Others respond to the survey (Atwater et al., 2007; Toegel \& Conger, 2003). Having two groups of respondents also enabled the self-perceptions of the Academic Directors to be compared to those who work alongside and observe the role in action.

As the $360^{\circ}$ feedback process was developmental and voluntary, both groups of participants were given the option not to have their data included in the present and any future studies. Only one Academic Director chose this option and their data was removed (together with the data of their eight Significant Others). Hence, 100 Academic Directors' data was analysed in this study. Of the 808 Significant Others who provided feedback on the 101 Academic Directors, 28 individuals also declined to have their data analysed. After removing their data and the eight Significant Others of the Academic Director who wished to be excluded from the analyses, the remaining sample for this data set was established. This data set is described in Table 1 .

Table 1: Sample Population for the Study

\begin{tabular}{|l|c|}
\hline \multicolumn{1}{|c|}{ Sample Population } & n \\
\hline Academic Directors & 101 \\
\hline Total Significant Others & 772 \\
\hline \multicolumn{1}{|c|}{ Subsets of Total Significant Others } & n \\
\hline Line Managers/Directors & 141 \\
\hline Peers (other Academic Directors) & 214 \\
\hline Course Coordinators (unit/subject coordinator) & 194 \\
\hline Professional Staff (administrative/general staff) & 223 \\
\hline
\end{tabular}

The Academic Directors were predominantly female (64\%), most of them (83\%) were between 40 and 59 years of age, and many of them (40\%) had held academic positions for more than 13 years. Most of the Academic Directors occupied more junior academic ranks, i.e. Lecturer Level B (45\%) or Lecturer Level C (45\%). As a group, they had been involved in university work for many years. However, a majority of them (59\%) had held their current 
Academic Director role for only one to four years, so in spite of their considerable years of work within the academic sector, they were fairly new to the Academic Director role. Some were very inexperienced (22\%) and had held the role of Academic Director for less than 1 year, while others $(19 \%)$ were very experienced in the role. Hence, there were large differences in experience in the sample. The majority of those (68\%) who had held the position for less than 1 year had no previous experience in an Academic Director's role.

The number of students enrolled in the Academic Directors' qualifications varied widely, with many Academic Directors (34\%) having 100 or fewer students, while others $(25 \%)$ had in excess of 400 students. In addition, $32 \%$ of Academic Directors worked with five or fewer teaching staff in their team, whereas $33 \%$ worked with 13 or more teaching staff in their team.

\section{Significant Others}

The Significant Others were also predominantly female (64\%) and most (67\%) were aged between 40 and 59. They held a range of academic positions and the majority (70\%) had been in their current position for 6 years or less.

\section{Academic Leadership Survey}

There were 16 items used to measure factors impacting on the Academic Director's performance (see Figure 1 for items). The questions were then developed further, based on discussions during initial workshops on a leadership program for Academic Directors (32 participants; see Vilkinas 2009). Responses were recorded on a 7-point Likert-type scale (1 = low impact, $7=$ high impact). The mean score on each item was calculated.

There were 14 items used to measure factors that would make the Academic Director's role more attractive (see Figure 2 for items) and were similarly reworked during the initial leadership workshops. Responses were recorded on a 7-point Likert-type scale $(1=$ not important, $7=$ very important $)$. The mean score on each item was calculated. 


\section{Data analyses}

The data on both the impact and the attractiveness scale items were analysed using repeated measures analyses of variance (ANOVA), because the dependent variables were perceptions related to the same person. This was followed by pairwise comparisons, to determine whether there were significant differences in the impact of the factors on the Academic Director's role and performance. Separate analyses were carried out for Academic Directors and for their Significant Others. The two groups were then compared using the non-parametric Wilcoxon signed-rank test.

\section{Results}

\section{Impact factors}

Academic Directors' perceptions

The repeated measures ANOVA for impact factors, with impact as the within-subjects factor, yielded a significant effect, $F(9.473,937.781)=23.94, p<.001$. Pairwise comparisons (with the Bonferroni adjustment) indicated that there were significant differences in the extent to which the factors impacted on job performance, as perceived by the Academic Directors. The mean scores (see Figure 1) indicated that the Academic Directors identified their workload to have the most significant impact on their performance $($ Mean $=6.52)$ which had significantly greater impact than all the other factors, with the exception of the combination of functions $($ Mean $=6.16)$. This second factor had a similar impact on the Academic Directors' performance as did the next seven factors: program knowledge $($ Mean $=5.96)$, range of people $($ Mean $=5.79)$, skills in working with academic staff $($ Mean $=5.73)$, with students $($ Mean $=5.73)$ and with support staff $($ Mean $=5.57)$, complexity of the role $($ Mean $=5.66)$ and discipline expertise $($ Mean $=5.23)$.

The next group of factors having a significantly lower impact were the remaining factors listed in Figure 1. These factors were around influence and authority, program nature, 
structural factors, marketing skills, previous experience and others' expectations. As all the means were greater than 4.35 (on a 7-point scale), this indicated that all the factors did have a strong to very strong impact on the Academic Directors' job performance.

[Insert Figure 1 about here]

\section{Significant Others' perceptions}

The repeated measures ANOVA for impact factors, with impact as the within-subjects factor, yielded a significant effect, $F(9.142,886.805)=54.13, p<.001$. Pairwise comparisons (with the Bonferroni adjustment) results indicated that there were significant differences in the extent to which the factors impacted on job performance, as perceived by the Academic Directors' Significant Others. The mean scores indicated that the Significant Others identified the Academic Directors' knowledge of the program structure $($ Mean $=6.12)$ and workload $($ Mean $=6.01)$ as having the most significant impact on their performance (see Figure 1$)$. Then there was a group of six factors having the next most significant impact (see Figure 1), namely, range of people $($ Mean $=5.76)$, skills in working with academic staff $(\mathrm{Mean}=5.69)$, with students $($ Mean $=5.76)$ and with support staff $($ Mean $=5.50)$, academic and administrative functions $($ Mean $=5.68)$, complexity of the role $($ Mean $=5.59)$ and discipline expertise $($ Mean $=5.49)$. The rest of the factors listed in Figure 1 had a significantly lower impact. These factors were around influence and authority, program nature, structural factors, marketing skills, previous experience and others' expectations. All the means were greater than 4.77 on a 7 -point scale and this indicated that the Significant Others believed that all the factors did have a strong to very strong impact on the Academic Directors' job performance.

When the perceptions of the two groups were compared, there were no significant differences on 13 of the 16 factors. That is, the Academic Directors and the Significant Others held the same perceptions of what impacted on the Academic Directors' job 
performance. The three factors that did differ were $\operatorname{workload}(z=-5.50, p<.01)$, academic and administrative functions $(z=-4.57, p<.01)$ and previous experience $(z=-2.83, p<$ .01). For the first two factors, the Academic Directors reported that the factors had significantly greater impact on their job performance than their Significant Others indicated. For the last factor, the reverse was true.

\section{Factors that would make the role more attractive}

Academic Directors' perceptions

The repeated measures ANOVA for importance of these factors, with the attractiveness as the within-subjects factor, yielded a significant effect, $F(8.869,878.065)=6.80, p<.001$. Pairwise comparisons (with the Bonferroni adjustment) results indicated that there were significant difference in the extent to which the factors impacted on the attractiveness of the role as perceived by the Academic Directors. The mean scores indicated that the Academic Directors identified several factors that have a highly significant impact on role attractiveness. These factors were promotion criteria $($ Mean $=5.83)$, credibility of the role $($ Mean $=5.81)$, workload points $($ Mean $=5.78)$, research time $($ Mean $=5.70)$, administrative support $($ Mean $=5.49)$, role clarity $($ Mean $=5.44)$, others' recognition $($ Mean $=5.35)$, allocated resources $($ Mean $=5.34)$ and support from professional staff $($ Mean $=5.15)$. The remaining factors listed in Figure 2 had a significantly lower impact on role attractiveness. These factors were around authority, study leave, pay, autonomy and type of administrative support. Given that all the means were greater than 4.81 (on a 7-point scale), this indicated that all the factors did have a strong to very strong impact on the potential attractiveness of the Academic Director's role. 
[Insert Figure 2 about here]

\section{Significant Others' perceptions}

The repeated measures ANOVA for impact factors, with attractiveness as the within-subjects factor, yielded a significant effect, $F(8.823,855.868)=32.04, p<.001$. The results of pairwise comparisons (with the Bonferroni adjustment) indicated that there were significant differences in the extent to which the factors impacted on the potential attractiveness of the Academic Director's role as perceived by their Significant Others (see Figure 2). Firstly, the Significant Others indicated that promotion criteria $($ Mean $=5.89)$ would have the strongest impact on role attractiveness. Secondly, the factors in the next group, workload points (Mean $=5.75)$, administrative support $($ Mean $=5.66)$, role credibility $($ Mean $=5.66)$ and recognition by others $($ Mean $=5.60)$, all had a similar impact on attractiveness and had a significantly stronger impact than the next group of factors. Thirdly, the factors in this third group included research time $($ Mean $=5.40)$, pay $($ Mean $=5.36)$, role clarity $($ Mean $=5.35)$, resources $($ Mean $=5.34)$, professional staff support $($ Mean $=5.31)$, authority $($ Mean $=5.24)$ and autonomy (Mean = 5.14). Fourthly, the factors in the third group had a significantly stronger impact on attractiveness than the last two factors, study leave and different type of administrative support. All the means were greater than 4.97 on a 7 -point scale indicating that the Significant Others believed that all the factors did have a strong to very strong impact on the attractiveness of the Academic Director's role.

When the perceptions of the two groups were compared, there were no significant differences on 13 of the 14 factors. That is, the Academic Directors and their Significant Others held the same perceptions of what impacted on the attractiveness of the Academic Director's role. The one factor on which the two groups differed was time for research $(z=$ $-2.73, p<.01)$. The Academic Directors reported that this factor had significantly greater 
impact on the attractiveness of their role job performance than their Significant Others indicated.

\section{Discussion}

\section{Impact factors}

One of the purposes of this study was to determine the factors that impacted on the job performance of the Academic Directors. Both the Academic Directors and their Significant Others were asked to indicate which factors had the most impact on the Academic Director role. In the main, there was agreement between the two groups who indicated that some factors had a greater impact on job performance than did others, with all the factors having a strong to very strong impact on the Academic Directors' job performance overall.

According to both the Academic Directors and their Significant Others, workload points had the strongest impact on the Academic Directors' performance. Byrne et al. (2012) previously found support for the impact of this factor on performance. The issue of academic workloads in the context of managerialism found its beginnings in the Dawkins White Paper on Higher Education when it announced sweeping changes to the system (Dawkins, 1988). This managerialism has resulted in higher workloads and fewer resources for academic staff (Anderson, 2006; Bellamy et al., 2003; Coates et al., 2010; Currie \& Vidovich, 1998) and a greater focus on outputs (Marginson, 2010) . Hence, a need for a more realistic workload allocation noted by these Academic Directors is not surprising.

In addition to this high impact factor was the complexity of the role which Vilkinas (2009) identified previously. The Academic Directors' knowledge and expertise was also regarded as having a very high impact. Such factors as program knowledge, discipline expertise, marketing skills and previous experience were all identified as having a very strong to strong impact. These factors have also been identified previously by Byrne et al. (2012) and Vilkinas (2009). This suggests that these positions require an appropriate job analysis to 
ensure that the people in these roles are given adequate time, support and training, in order for them to be successful in the role.

The next group of factors to impact on the Academic Directors job performance were related to the work relationship area: range of people, skills in working with academic staff, with students and with support staff. These people skills were found to have a stronger impact on the Academic Directors' performance than did the significant others' expectations. This is also not a surprise since half of the growth in staffing across Australian universities has been in casual staff (Coates et al., 2010). Academic Directors would have increasing responsibilities working with this growing cohort of staff and the turnover associated within this staffing cohort. People skills have been reported to have an impact on performance (Byrne et al., 2012; Wong and Heng 2009). This finding suggests that individuals selected for this position require high level interpersonal and communication skills and may require further training and support to achieve expected performance levels. The possession of these important skills suggests that recruitment efforts be targeted towards finding the most suitable candidate for the Academic Director position - rather than what often happens is the positioning of a reluctant staff member in to this role.

The factors in the next group were associated with influence and authority, and influencing peers, with some having a significantly stronger impact than others. Byrne et al. (2012), Coates et al. (2009) and Vilkinas (2009) reported on the significant impact of autonomy on performance and note the difficulties of leading and managing when no formal authority exists. Leading through influence and through the use of social emotional intelligence becomes more important in these roles where power is distributed. Again recruitment of individuals with strong skills in these areas, along with further leadership training and development, would support incumbents in the Academic Director role (Ladyshewsky \& Flavell, 2012). 
Finally, structural factors had a lower (but still strong) impact. Vilkinas (2009) has previously found support for the impact of this factor on performance and again denotes the importance of understanding this role and its job design.

\section{Factors that would make the role more attractive}

The second purpose of this study was to determine which factors impacted on the attractiveness of the Academic Directors' role. It is important that staff be satisfied and motivated in their jobs (Coates et al., 2010). The participants in this study may have been more motivated than the population sample as they generally volunteered to participate in the leadership development program and survey. Both the Academic Directors and their Significant Others were asked to indicate which factors had the most impact. In the main, there was agreement between the two groups who indicated that some factors had a greater impact on attractiveness than did others, with all the factors having a strong to very strong impact on the attractiveness of the Academic Directors' role.

There were a group of factors around working conditions. They were research time, automatic study leave, pay, more resources such as administrative and professional support, different type of administrative support, recognition of the role, credibility of the role and allocated workload points. Some of these factors had a stronger impact on attractiveness than others. For example, allocated workload points and research time had a greater impact than increased resources. This is not surprising as it would enable people to fulfil the expectations of their role more comprehensively. Vilkinas (2009) has previously found support for the impact of all these factors on the attractiveness of the role and several other researchers have found support for the impact of pay (Byrne et al., 2012; Coates et al., 2009; Lazarsfeld Jensen \& Morgan, 2009; Mercer, 2009; Wong \& Heng, 2009) and others have also reported the impact of promotion on role attractiveness (Al-Rubaish et al., 2009; Byrne et al., 2012; Lindner, 1998; Vilkinas, 2009; Wong \& Heng, 2009). Again this points to the need for good 
job design and analysis, and having policies in place that demonstrate the role is valued and one that will support movements towards promotion. It may be worthwhile, therefore, to consider changing the Academic Director role from what are often short term positions to formally appointed ones with clear job descriptions, longer terms, requiring stronger academic and administrative leadership (Meek, Goedegeburre \& de Boer, 2010).

The remaining factors were linked to autonomy and authority, clarity of work goals and expectations of others. All these factors had a similar impact on the attractiveness of the role and have previously been identified by Byrne et al. (2012), Coates et al. (2009) and Vilkinas (2009).

This research is not suggesting that these individuals are ineffective in their roles. What it is indicating is that there are significant impact factors which, if addressed, could further improve the working conditions of these important positions - although this could be more costly. One study by Vilkinas and Ladyshewsky (2012) demonstrated that Academic Directors were considered to perform effectively in their role. The results indicated that they focussed on getting the job done (e.g. running the course) and working with people (e.g. staff and student issues). However, what was not being addressed to the same degree by these same Academic Directors was monitoring of the program (e.g quality indicators), maintaining networks (e.g. ensuring strong links with industry) and managing change. As a result they were putting their programs at risk in the long term even though they appeared to be effective in the short term. Addressing some of the impact factors identified in this research would likely change this focus. 
What is clear as well from the findings of this research are that many of the factors impacting on performance and on attractiveness are outside of the control of these individuals. Most of the Academic Directors in this study are in junior ranks and are likely to experience less satisfaction and influence than those of their senior counterparts. This is supported by the CAP survey findings which found those in senior ranks reported higher levels of satisfaction and felt more involved in decision making (Coates, et al., 2010).

Academic Directors can obtain experience to strengthen their leadership skills, improve interpersonal communication and gain further knowledge of the institutional policies and program. Such leadership development programs, when delivered within universities, with appropriate time release can strengthen leadership skills at the Academic Director level (Ladyshewsky \& Flavell, 2012). However, obtaining training and gaining experience are only partial strategies for improving one's success in this role and more situated development is also required.

Many of the issues impacting on performance and job attractiveness relate to structural factors within the institution and policy frameworks which often lean towards promoting teaching and research - although there is an increasing recognition within universities to recognise the importance of both equally. For example, workload allocation is based on a formula which is set by the institution. The result is that Academic Directors have neither the power nor the necessary standing within the university to alter any of these factors, particularly if they are junior staff. It is the responsibility of senior management and the Academic Directors' Line Managers, therefore, to show leadership by addressing these through job design factors in workload allocations and through university policies and procedures. This creates an opportunity to improve overall course quality through providing those responsible for this task with the appropriate resources. It also creates opportunities for making these roles attractive within the context of the university and it's culture. This 
research is not suggesting that Academics are not doing their job effectively, however it is suggesting that there is considerable room for improvement in job design. These considerations are described below.

Hence, this research provides a range of data that enables further discussion on the Academic Director role. Given the findings of this research, in combination with the literature, the following suggestions are made regarding job design factors and the impact on the Academic Director role.

- Selection criteria for positions should stipulate the need for people management skills, program and discipline knowledge, and previous experience. In some cases this may not be possible to find in-house and external recruitment would become necessary. In other instances succession planning would facilitate entrance in to these roles.

- Training and development opportunities should be provided to enhance the leadership capability of Academic Directors to influence others, particularly when they do not have a formal power relationship. This training has to be experiential and situated within the role with opportunities for peer coaching and peer collaboration. Formal training (e.g. courses and readings) are only a part of the overall training strategy.

- Policies should be developed/reviewed to more accurately capture workload point allocations for the role, level of authority and structural factors in order for individuals in these roles to be able to deliver the outcomes set forth by their senior leaders.

- Academic Directors' Line Managers must become more involved in discussions about the expectations of the role, the nature of the program, and how the role is organised.

By taking into consideration the data presented in this research along with the information in the literature, there is also an opportunity for discussion on how to make these roles more attractive to individuals within universities. Some of these considerations are described below. 
- Policies that enable Academic Directors to have more research time and automatic study leave at the end of their term may entice more individuals in to the role. Such policies would reduce concerns that such roles are career advancement dead-ends because they do not fit neatly into the teaching and research context of universities.

- Promotion opportunities were linked to the role.

- Adequate resources were allocated to support the role.

\section{Strengths and limitations}

The main strengths of this study are that:

- it is one of the first of this kind to be undertaken in academia to explore the issues related to the Academic Director role; and

- it researches an important leadership role in the management of universities.

The individuals in these roles can have a major impact on the quality and reputation of an educational qualification. Hence, the role should not be overlooked and forgotten just because of its lower 'middle' manager status. This research also provides senior leaders in academic settings with information they can consider to improve the attractiveness and potential of these important positions.

As universities become scrutinized more and more, the quality of leadership and management of academic qualifications increases. Hence, understanding the complexities of the Academic Director role and putting in place strategies to support this key position should yield more positive results for universities and their student cohorts.

There are also some limitations to this study. A larger sample size and exploring these factors in different cultural settings would also address some of the limitations pertaining to generalizability. As the sample in this research involved volunteer participants and those nominated by their managers, a larger sample size would also capture the voices of other Academic Directors who might be required or advised to attend training. This other group 
may have additional or different views about impact and attractiveness factors. Adapting the questionnaire to different academic management roles within the university could also be useful, to see how transferable some of these impact factors are to other positions (e.g. Deans, Heads of Schools).

\section{Conclusion}

This research has described a range of factors which impact on the role of Academic Director and also provides some data on what might make the role more attractive. Universities can use this information to improve aspects of the Academic Director role where it is considered to be ineffective. The Academic Role is an important position linked to quality outcomes for universities. Greater effort by senior leaders of universities needs to be put into developing adequate policies and procedures to make this role more attractive. Making the role more attractive will entice staff to these important roles and enable Academic Directors to perform well in the job.

The senior leadership of universities also need to consider the results of this research seriously. If senior leaders are committed to quality outcomes in their qualifications, they have a responsibility to ensure that those responsible for producing these outcomes can do so effectively and efficiently. The quality of a degree program requires individuals who can manage the program exceedingly well. They have to be attracted to the job and want to perform well. This research will also provide some background information to those academic staff interested in applying for an Academic Director role. By addressing the impact factors noted in this research, quality outcomes are possible, along with a selfactualised and motivated workforce committed to excellence in qualification delivery. 


\section{References}

Al-Rubaish, A.M., Rahim, I.A., Abumadini, M.S. and Wosornu, L. (2009), "Job satisfaction among the academic staff of a Saudi university: an evaluative study", Journal of Family and Community Medicine, Vol. 16 No. 3, pp. 97-103, available at: http://www.ssfcm.org/english/index.php?fuseaction=content. main\&mainsection=000000 0893\&artical=0000001954\&page\%5B1\%5D=1 (accessed 17 May 2012).

Anderson, G. (2006) "Carving out time and space in the managerial university", Journal of Organizational Change Management, 19:5;578 - 592.

Atwater, L.E., Brett, J.F. and Charles, A.C. (2007), "Multisource feedback: lessons learned and implications for practice", Human Resource Management, Vol. 46 No. 2, pp. 285307. doi: 10.1002/hrm.20161

Bellamy, S,. Morley, C., and Watty, K. (2003), "Why Business Academics Remain in Australian Universities Despite Deteriorating Working Conditions and Reduced Job Satisfaction : An Intellectual Puzzle", Journal of Higher Education Policy and Management, 25:1;13-28

Byrne, M., Chughtai, A.A., Flood, B. and Willis, P. (2012), “Job satisfaction among accounting and finance academics: empirical evidence from Irish higher education institutions", Journal of Higher Education Policy and Management, Vol. 34 No. 2, pp. 153-67. doi: 10.1080/1360080X.2012.662740

Coates, H., Dobson, I., Goedegebuure, L., and Meek, L. (2010) Across the great divide: what do Australian academics think of university leadership? Advice from the CAP Survey. Journal of Higher Education Policy and Management. Vol. 32 No 4, pp. 379-387.

Coates, H., Dobson, I., Edwards, D., Friedman, T., Goedegebuure, L. and Meek, L. (2009), The Attractiveness of the Australian Academic Profession: A Comparative Analysis, research briefing, Australian Council for Educational Research, Camberwell, Victoria.

Currie, J. and Newson, J. (1998) Universities and Globalization: Critical Perspectives. Sage, Thousand Oaks, California.

Currie, J. and Vidovich, L. (1998) The Ascent Towards Corporate Managerialism in American and Australian Universities, in Martin, R (Ed.) Chalklinkes - The Politics of Work in the Managed University, Duke University Press, London. Pp. 112-144.

Currie, G. and Procter, S. (2005) The Antecedents of Middle Managers' Strategic Contribution: The Case of a Professional Bureaucracy. Journal of Management Studies. Vol. 42 No. 7, 1325 - 1356. DOI: 10.1111/j.1467-6486.2005.00546.x

Dawkins, J. (1998) Higher Education - A Policy Statement, Australian Government Publishing Service, Canberra

de Boer, H. and Goedegebuure, L. (2009), "The changing nature of the Academic Deanship", Leadership, Vol. 5 No. 3, pp. 347-64. doi: 10.1177/1742715009337765

de Boer, H., Goedegebuure, L., and Meek, L. (2010) The changing nature of academic middle management: A framework for Analysis. In VL Meek et al. (Eds) The Changing Dynamics of Higher Education Middle Management. Higher Education Dynamics. Vol. 33. pp. 229-241. DOI 10.1007/978-90-481-9163-5_3. Springer 
Deem, R., Hillyard, S., and Reed, M. (2007) Knowledge, Higher Education, and the New Managerialism: The Changing Management of UK Universities. Oxford University Press, Oxford.

Harvey, L. and Knight, P. (1996) H. Open University Press, Taylor and Francis. Bristol, United Kingdom.

Holmes, (1993) Quality Assurance in Further and Higher Education: A Sacrifical Lamb on the Altar of Managerialism. Quality Assurance in Education, 1:1;4.

Iaffaldano, M., and Muchinsky, P. (1985) Job Satisfaction and Job Performance. Psychological Bulletin, 97;2; 251-273.

Johnson, R. (2002) Learning to Manage the University: Tales of Training and Experience, Higher Education Quarterly, 56:1;33-51.

Judge, T., Thorenson, C., Bono., J. and Patton, G. (2001) The job satisfaction-job performance relationship: A qualitative and quantitative review, Psychological Bulletin, $127: 3 ; 376-407$.

Ladyshewsky, R. and Flavell, H. (2012) Transfer of Training in an Academic Leadership Development Program for Program Coordinators. Educational Management Administration and Leadership, 40:1;127-147.

Lazarsfeld, Jensen, A. and Morgan, K. (2009), Overload - the Role of Work-Volume Escalation and Micro-Management of Academic Work Patterns in Loss of Morale and Collegiality at UWS: The Way Forward, research report, National Tertiary Education Union, South Melbourne, Victoria, Australia.

Lindner, J.R. (1998), “Understanding employee motivation”, Journal of Extension, Vol. 36 No. 3. Available at: http://www.joe.org/joe/1998june/rb3.php (accessed 17 May 2012).

Marginson, S (2010) The Limits of Market Reform in Higher Education, Higher Education Reform, 7;1-19.

McRoy I and Gibbs P (2009) Leading change in higher education. Educational Management Administration \& Leadership 37(5): 687-704.

Mercer, J. (2009), "Junior academic-manager in higher education: an untold story?", International Journal of Educational Management, Vol. 23 No. 4, pp. 348-59. doi 10.1108/09513540910957444

Meek, V., Goedegebuure, L., Santiago, R., and Carvalho, T. (2010) Introduction. In VL Meek et al. (Eds) The Changing Dynamics of Higher Education Middle Management. Higher Education Dynamics. Vol. 33. pp. 1- 14. DOI 10.1007/978-90-481-9163-5_3. Springer.

Petty, M., G., and Cavender, J. (1984) A Meta-Analysis of the Relationships Between Individual Job Satisfaction and Individual Performance. Academy of Management Review, 9:4;712-721.

Toegel, G. and Conger, J.A. (2003), “360-degree assessment: time for reinvention”, Academy of Management Learning and Education, Vol. 2 No. 3, pp. 297-311.

Vilkinas, T., Ladyshewsky, R.. (2012) Leadership Behaviour and Effectiveness of Academic Program Directors in Australian Universities. Educational Management Administration and Leadership. 40:1;109-126. 
Vilkinas, T. (2009), Improving the Leadership Capability of Academic Coordinators in Postgraduate and Undergraduate Programs in Business, final report, Australian Learning and Teaching Council, Surry Hills, New South Wales, available at:

http://www.olt.gov.au/system/files/resources/Improving\%20the\%20leadership\%20capacit y\%20-\%20UniSA\%20Apr09.pdf (accessed 16 October 2012).

Wong, E.S.K. and Heng, T.N. (2009), "Case study of factors influencing jobs satisfaction in two Malaysian universities", International Business Research, Vol. 2 No. 2, pp. 86-98, available at: http://www.ccsenet.org/journal/index.php/ibr/article/viewFile/1123/1125 (accessed 17 May 2012). 


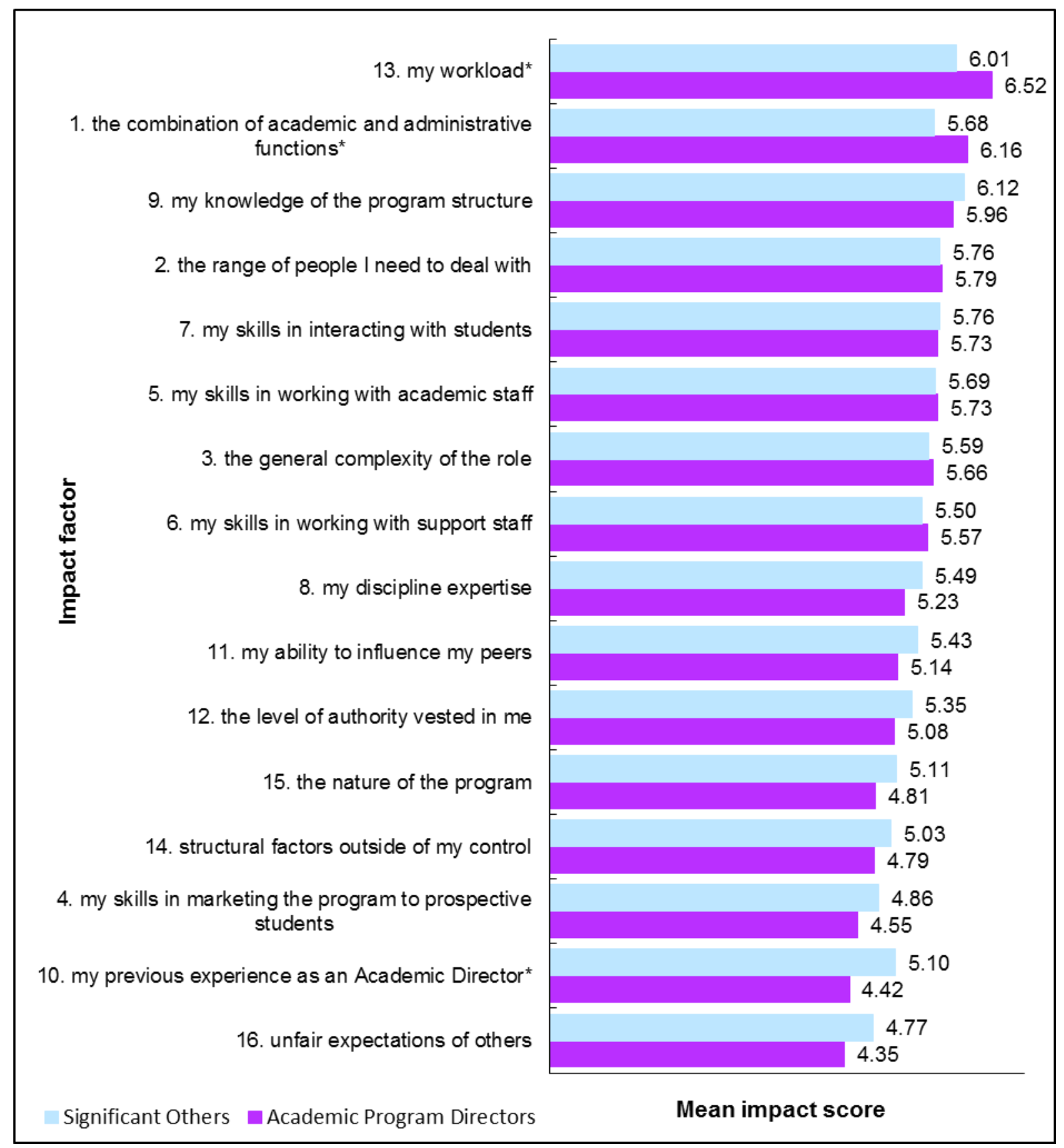

Figure 1. Mean scores on factors impacting on Academic Directors' job performance, as perceived by the Academic Directors and their Significant Others. (The asterisks denote the three items on which the two groups differed significantly.) 


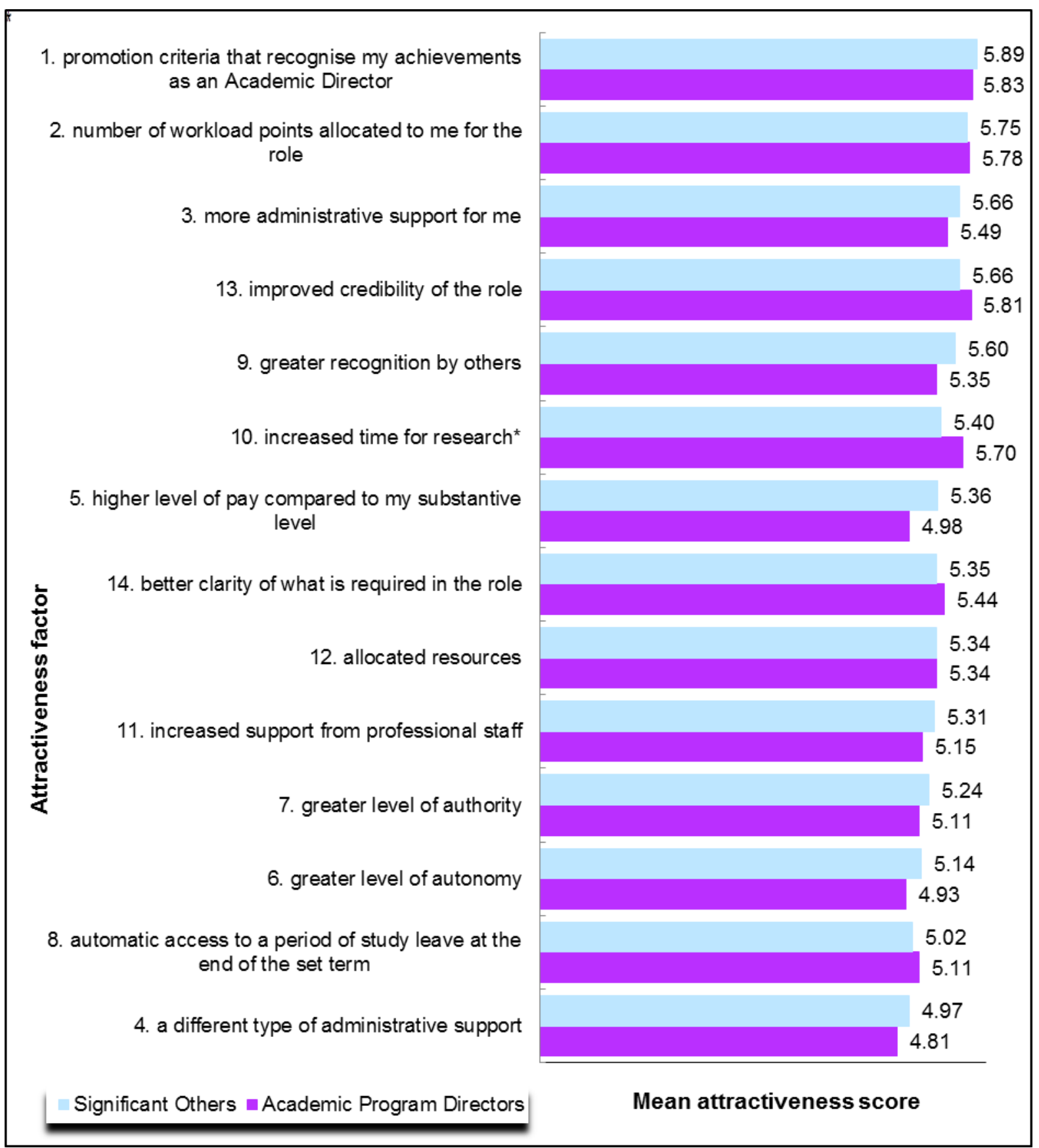

Figure 2. Mean scores on factors impacting on attractiveness of Academic Directors' role, as perceived by the Academic Directors and their Significant Others* 